\title{
RESPIRATORY SYMPTOMS AND LUNG FUNCTION IMPAIR- MENT IN UNDERGROUND GOLD MINERS IN GHANA
}

\author{
"F.Y. BIO, S. SADHRA ${ }^{1}$, C. JACKSON ${ }^{2}$ and P.S. BURGE ${ }^{3}$ \\ University Health Services, Kwame Nkrumah University of Science and Technology, Kumasi, \\ Ghana. ${ }^{1}$ Institute of Occupational and Environmental Medicine, University of Birmingham, UK. \\ ${ }^{2}$ School of Health and Policy Studies, University of Central England in Birmingham, UK. \\ ${ }^{3}$ Department of Respiratory Medicine, Birmingham Heartlands Hospital, Birmingham, UK
}

\section{SUMMARY}

Background: This is the first study in Ghana in the Obuasi gold mines where the silica content of the respirable dust is $10 \%$, less than in previously studied gold mines, with only $23 \%$ of the miners having ever smoked.

Objectives: The study was to assess the prevalence of respiratory impairment in the Ghanaian gold miner and to quantify the effects of the respirable dust on pulmonary function

Design: A cross sectional epidemiological study

Method: The study was carried out using MRC respiratory symptoms questionnaire, spirometry, and personal respirable dust measurements.

Results: A total of 1236 miners were studied. The mean age was $39.7 \pm 5.8(\mathrm{SD})$ years with a mean of $12.6 \pm 6.7(\mathrm{SD})$ years underground service and a mean total cumulative exposure to dust of 10.34 \pm 5.61 (SD) $\mathrm{mg} \cdot \mathrm{m}^{-3}$.years. The prevalence of chronic bronchitis was $21.2 \%$ and not clearly related to cumulative exposure. MRC breathlessness grade $\geq 2$ was $31.3 \%$, significantly related to cumulative respirable dust exposure after adjustment of age and smoking. There was however significant reduction in $\mathrm{FEF}_{25-75 \%}$ with increasing dust exposure and an interaction with ever smoking. There was no correlation between cumulative exposure to respirable dust and $\mathrm{FEV}_{1} \%$ predicted in any group, suggesting that exposure to respirable silica at a mean level of $0.06 \mathrm{mg} / \mathrm{m}^{3}$ had no deleterious effect on $\mathrm{FEV}_{1}$ in a population with little tuberculosis, good housing and a low level of cigarette smoking.

Conclusion: The prevalence of chronic bronchitis in the Ghanaian gold mine is related more to smoking than any occupational factors

Keywords: Gold mining; respirable dust; chronic bronchitis; lung functions; breathlessness

\section{INTRODUCTION}

Numerous epidemiological studies have supported the association between respiratory impairment and occupational exposure to dust ${ }^{1}$. Studies in South African gold mines have observed dose related declines in $\mathrm{FEV}_{1}$, unrelated to radiological pneumoconiosis, but related to cumulative silica exposure and smoking pack years, with an interaction between silica exposure and smoking ${ }^{2}$. Many of the workers studied were migrants living in hostels with a high incidence of tuberculosis.

The Obuasi gold mine in Ghana employs about 2,500 workers (both underground miners and surface workers) mainly Ghanaians who live with their families. Smoking is infrequent in the miners. The respirable dust of the gold mine ore contains only $10 \%$ respirable silica ${ }^{3}$. This gives an opportunity to investigate the health effects of low level silica exposure in a predominantly well nourished, non-smoking population.

The main objectives of the study were to determine the type and extent of occupational lung disease in the underground gold miners by the use of questionnaire, sputum examination and lung function testing, to quantify personal exposure to respirable dust and silica and to estimate cumulative exposure. It was also to determine the nature of any relationship between dust exposure and respiratory disorders.

\section{MATERIALS AND METHODS \\ Population}

The study population was all male Ghanaian underground gold miners and engineers (electrical and mechanical) in the north, central and south mines of Obuasi, and with current full time employment in the mines for duration of at least one year at the time of the study. The study period was from the start of June to mid-November 2001.

\footnotetext{
${ }^{*}$ Author for correspondence biov97@yahoo.co.uk
} 
Ethical clearance to undertake the study was obtained from the Research Ethics Committee of the School of Medical Sciences, Kwame Nkrumah University of Science and Technology, Kumasi, Ghana.

\section{Occupational Groups}

The miners were classified into eight different occupational groups. An occupational group represents a group of miners who perform similar work under similar working conditions irrespective of job title. The seven main groups were as follows: drilling, blasting, mucking/loading, tramming, tipping/skipping/rock-breaking, supervisory and engineering; and an eighth (other) occupational group comprising a combination of all the lesser occupations in which the miner spends most or his entire shift underground. These include pipe/trackfitting, welding, shaft tending, pumps attendance and grouting. These occupations are directly related to the production and removal of ore and rock, and are therefore considered to have high dust exposure. The underground gold mining operations involve drilling, blasting, loading, transporting and tipping of ore before it is hoisted to the surface.

Each sampled worker was studied by interviewer administered questionnaire and lung function test by spirometry. A $10 \%$ sample in addition had bacteriological examination of sputum and personal respirable dust measurements during a full working shift.

\section{Questionnaire}

The respiratory questions were modified from the British Medical Research Council ${ }^{4}$, and the International Union against Tuberculosis and Lung Diseases ${ }^{5}$ respiratory symptom questionnaires. The questionnaire was aimed at diagnosing chronic bronchitis, assessing other respiratory symptoms and disability, and obtaining information on possible confounding factors.

Additional questions dealt with the duration of employment in the mine, current and previous mine work, as well as any previous work involving exposure to airborne dusts; such as mine, quarry or other dusty environments. There were also questions on tobacco smoking, current or previous respiratory disease, chronic bronchitis, bronchial asthma and current drug treatment, as well as a personal or family history of tuberculosis,

The questionnaire was pre-tested, both by selfadministration as well as by interview in the local language, 'Asante Twi', on about 50 Ghanaian residents in Birmingham for their understanding and comments after which the final questionnaire was developed. No Ghanaian language version of the questionnaire was developed, but the questionnaire was read in English and translated into Twi. The questionnaire was administered by one trained assistant (a science graduate). The workers were interviewed before their daily (morning or afternoon) shifts began.

\section{Lung Function tests}

Spirometry was performed to ATS/ERS standards ${ }^{6}$, ${ }^{7}$ by one author and the questionnaire administrated by an assistant. The Micro-Loop II 'Gold Standard' spirometer (Micro-Medical Limited, United Kingdom, was used. Spirometry was carried out sitting at an ambient room temperature of between $23^{\circ} \mathrm{C}$ and $27^{\circ} \mathrm{C}$, depending on the time of the day. The spirometer was calibrated daily with a 3-litre calibration syringe and as required by $\mathrm{ATS}^{6}$. The best of at least three manoeuvres of FVC (Forced Vital capacity), FEV 1 (Forced Expiratory Volume in one second), and forced mid-expiratory flow $\left(\mathrm{FEF}_{25-75 \%}\right)$ were recorded using the SPIDA ${ }^{8}$.

Body weights were measured in kilograms and sitting and standing heights were measured to the nearest centimetre, both without boots.

\section{Personal dust sampling}

Personal respirable dust gravimetric analysis was undertaken on a sample of $125(10 \%)$ of the 1236 subjects from June to middle of November 2001. Details of personal dust sampling have been reported elsewhere 9 . The same individuals provided spontaneously expectorated sputum for ZeihlNielsen staining.

\section{DATA ANALYSIS \\ Demographic characteristics}

Frequency distributions, group means, confidence intervals and standard deviations were calculated with the standard descriptive statistics. Categorical data were calculated in percentages and continuous data in means and standard deviations. Five binary indicators were used to represent the age groups $<25,25-34,35-44,45-54$ and 55 years or more. The few who were younger than 25 and older than 55 years were not used in any further analyses. The ever-smoked group, 'have you ever smoked as much as one cigarette a day for as long as one year?' was created due to the small numbers of the current and ex-smokers. The total duration of underground service was also categorised into five 
groups as: 1-5, 6-10, 11-15, 16-20 and 21-35 years.

\section{Respiratory Symptoms}

The prevalence of chronic bronchitis was derived from positive response to both of the following questions: "do you cough like this on most days for as much as three months each year for 2 consecutive years?" and "do you bring up phlegm like this on most days for as much as three months each year for 2 consecutive years?"

The prevalence of Medical Research Council (MRC) breathlessness grade was derived from a "yes" response to the following questions "are you troubled by shortness of breath when hurrying on a level ground or walking up a slight hill?" as grade one; "do you get short of breath walking with other people of your own age on level ground?" as grade two; and "do you have to stop for breath when walking at your own pace on level ground?" as grade three.

The determinants of respiratory symptoms were analysed through chi-square tests and then by binary logistic regression (SPSS). The logistic regression models used included age, total duration of underground service, and current and total cumulative respirable dust exposures. Each indicator was analysed separately for its effect on the respiratory symptom without smoking and then simultaneously with smoking in the logistic regression model. Analysis of Variance (ANOVA) was also used to establish the relationship between mean breathless grade, total cumulative respirable dust exposure and ever/never smoking.

\section{Pulmonary Function Tests}

Mean lung function values were calculated for all anthropometric characteristics (age, height and weight and body mass index), smoking, and total cumulative respirable dust exposure, as the independent variables. The dependent variables were the individual lung function measurements. The effects of the above variables on lung function levels were assessed by multiple linear regression analysis, both individually and simultaneously to identify significant determinants.

Analysis of Variance (ANOVA) was also used to determine the relationship between the various lung function indices, i.e. $\mathrm{FEV}_{1} / \mathrm{FVC}, \mathrm{FEV}_{1}(\%$ predicted), FVC ( $\%$ predicted) and $\mathrm{FEF}_{25-75 \%}(\%$ predicted), and total cumulative respirable dust exposure and smoking. Predicted values were taken from the ECCS equations with a conversion factor of 0.87 for the volume measurements (Bio FY, Sadhra S, Jackson C, Burge PS. Pulmonary function prediction equations of male gold miners in Ghana. (Submitted to GMJ)).

\section{RESULTS}

\section{Demographic characteristics}

A total of 1243 miners were interviewed from the total available underground workforce of 1465 . Seven miners had to leave the interview before completing the questionnaire in order to report for underground work; 1236 miners completed the questionnaire. In addition, a total of 280 miners were on annual leave during the study period, and about 30 were on sick leave due to injury and other ailments unrelated to the lungs, and could not therefore participate in the study. A response rate of $84.4 \%$ was achieved for the questionnaire.

The mean age of the miners was 39.7 years (S.D \pm $6 y)$. Only $0.6 \%$ of miners were less than 25 or over 55 years of age. Their mean heights and weights were $170 \mathrm{~cm}(\mathrm{~S} . \mathrm{D} \pm 6.0)$ and $67.3 \mathrm{~kg}(\mathrm{~S} . \mathrm{D} \pm 9.9)$ respectively. The mean body mass index (weight/height ${ }^{2}$ ) was $23.3(\mathrm{~S} . \mathrm{D} \pm 3$ ), indicating no obesity in the population. Table 1 shows the demographic distribution of the miners.

Table 1 Demographic distribution of the miners

\begin{tabular}{|c|c|c|}
\hline Variables & $\mathbf{n}$ & $(\%)$ \\
\hline Age $(y)$ : mean $=39.7$, sd $=5.8$ & & \\
\hline $25-34$ & 235 & $(19.1)$ \\
\hline $35-44$ & 725 & $(59.0)$ \\
\hline $45-54$ & 269 & $(21.9)$ \\
\hline Smoking status & 945 & \\
\hline Never smoked & 64 & $(76.9)$ \\
\hline Current smoker & 220 & $(5.2)$ \\
\hline Ex-smoker & & $(17.9)$ \\
\hline $\begin{array}{l}\text { Cigarette-years (c.y): } \\
\text { mean }=46, s d=69.3\end{array}$ & 945 & \\
\hline 0 (never smoked) & 252 & $(76.9)$ \\
\hline $1-100$ & 32 & $(20.5)$ \\
\hline $101+$ & & (2.6) \\
\hline $\begin{array}{l}\text { Total duration underground } \\
\text { work }(y)^{*}: \text { mean }=12.6, \mathrm{sd}=6.7\end{array}$ & 234 & \\
\hline $1-5$ & 252 & $(19.1)$ \\
\hline $6-10$ & 235 & $(20.5)$ \\
\hline $11-15$ & 368 & $(19.1)$ \\
\hline $16-20$ & 139 & $(30.0)$ \\
\hline $21-35$ & & $(11.3)$ \\
\hline  & 591 & \\
\hline$<10$ & 582 & 48.1 \\
\hline $10-19.99$ & 55 & 47.4 \\
\hline 20-39.99 & & 4.5 \\
\hline
\end{tabular}


There was little variation in the housing facilities enjoyed by the miners; $98 \%$ lived with their families. Similarly, though wood fires may contribute to airflow limitation, the cooking in childhood days of almost all the miners $(97.6 \%)$ was with wood. No further analyses were made of housing and the mode of cooking.

Most miners had never smoked (76.9\%), 17.9\% were ex-smokers, whilst just 5.2\% were currently smoking. The mean cigarette-years (c.y) (Number of cigarettes/day $x$ years smoked) was 46 (S.D \pm 69.3 c.y). The mean total duration of underground work (total exposure) was 12.6 years $(S . D \pm 6.7 y)$, posure, cumulative respirable dust exposure and total duration of mine work. The overall prevalence of chronic bronchitis was $21.2 \%$. There was an increasing effect, though not significant, of age on chronic bronchitis until about 44 years and then a decrease, both before and after adjustment for smoking. There was significant effect $(\mathrm{p}=0.049)$ OR 1.37 (95\% CI 1.00 to 1.87) of smoking, before adjustment for age on chronic bronchitis (Table 2). Tipping/rock-breaking was associated with an increased prevalence of chronic bronchitis $(\mathrm{p}=0.045)$, OR 1.93 (95\% CI 1.02 to 3.67), before adjustment for smoking (Table 2). The overall effect of current occupations and current exposure

Table 2 Prevalence of chronic bronchitis in relation to age, current occupation, total cumulative exposure to dust and smoking status of miners

\begin{tabular}{|c|c|c|c|c|c|c|}
\hline \multirow{2}{*}{$\frac{\text { Variables }}{\text { Age groups }(y)}$} & \multirow[t]{2}{*}{$\begin{array}{c}\text { No chronic } \\
\text { bronchitis } \\
\text { n } \\
\end{array}$} & \multirow[t]{2}{*}{$\begin{array}{c}\text { Chronic } \\
\text { bronchitis } \\
\text { n } \\
\end{array}$} & \multicolumn{2}{|c|}{$\begin{array}{l}\text { Odds ratio }(95 \% \mathrm{CI}) \\
\text { (separate analysis) }^{\mathrm{a}}\end{array}$} & \multicolumn{2}{|c|}{$\begin{array}{c}\text { Odds ratio (95\% CI) } \\
\text { (simultaneous analy- } \\
\text { sis) }^{\mathrm{b}} \\
\end{array}$} \\
\hline & & & & & & \\
\hline $25-34$ & 193 & 42 & 1.00 & & 1.00 & \\
\hline $35-44$ & 561 & 164 & 1.34 & (0.92 to 1.96$)$ & 1.30 & (0.88 to 1.92$)$ \\
\hline $45-54$ & 215 & 54 & 1.15 & (0.74 to 1.81$)$ & 1.10 & (0.68 to 1.76$)$ \\
\hline \multicolumn{7}{|c|}{$\begin{array}{l}\text { Total cumulative expo- } \\
\text { sure }\left(\mathrm{mg}^{-3} \mathrm{~m}^{-3} \cdot \mathrm{y}\right)\end{array}$} \\
\hline$<10$ & 471 & 120 & 1.00 & & 1.00 & \\
\hline $10-19.99$ & 450 & 132 & 1.15 & (0.87 to 1.52$)$ & 1.06 & (0.78 to 1.44$)$ \\
\hline $20-39.99$ & 47 & 8 & 0.67 & (0.31 to 1.45$)$ & 0.65 & (0.29 to 1.46$)$ \\
\hline \multicolumn{7}{|c|}{ Current occupations +} \\
\hline Other & 128 & 25 & 1.00 & & 1.00 & \\
\hline Tramming & 146 & 29 & 1.02 & (0.57 to 1.83$)$ & 1.00 & (0.55 to 1.78$)$ \\
\hline Mucking & 109 & 35 & 1.64 & (0.93 to 2.92$)$ & 1.63 & ( 0.92 to 2.90$)$ \\
\hline Blasting & 140 & 46 & 1.68 & (0.98 to 2.89$)$ & 1.62 & (0.94 to 2.79$)$ \\
\hline Engineering & 116 & 32 & 1.41 & (0.79 to 2.52$)$ & 1.47 & $(0.82$ to 2,64$)$ \\
\hline Supervisory & 51 & 12 & 1.21 & (0.56 to 2.58$)$ & 1.20 & (0.56 to 2.58$)$ \\
\hline Tipping/R-B & 61 & 23 & $1.93 *$ & (1.02 to 3.67$)$ & 1.86 & (0.98 to 3.55$)$ \\
\hline Drilling & 218 & 58 & 1.36 & (0.81 to 2.28$)$ & 1.36 & (0.81 to 2.29$)$ \\
\hline \multicolumn{7}{|l|}{ Smoking status } \\
\hline Never smoked & 756 & 188 & 1.00 & & 1.00 & \\
\hline Ever-smoked & 212 & 72 & $1.37 *$ & (1.00 to 1.87 ) & 1.33 & (0.97 to 1.84$)$ \\
\hline Total & 969 & 260 & & & & \\
\hline
\end{tabular}

whilst a mean of 9.4 years $(S . D \pm 5.9 y)$ had been spent at the current occupation. Most of the miners had no previous mining/dust exposure, though $6.6 \%$ have either been in other underground gold mine $(5.3 \%)$, surface gold mine or gold processing $(0.7 \%)$.

\section{Determinants of respiratory symptoms}

The prevalence of questionnaire defined chronic bronchitis was compared with current job and ex- on chronic bronchitis was however not significant $(\mathrm{p}=0.187)$.

Chronic bronchitis showed a non-significant increase with total duration of underground service, peaking in the second decade and then declining in the third decade, before and after adjustment for smoking. The effect of total cumulative respirable dust exposure on the prevalence of chronic bronchitis among the miners increased with in- 
creasing exposure before and after adjustment for cigarette smoking. The increasing effect was observed up to a maximum total cumulative exposure of $20 \mathrm{mg} \cdot \mathrm{m}^{-3} . \mathrm{y}$, after which it waned. The effect was however not significant $(\mathrm{p}=0.384)$.

The prevalence of MRC breathless grade $\geq 2$ or more was $31.3 \%$. Breathless grade was significantly related to age, smoking, duration of underground mining and cumulative respirable dust exposure. The increasing effect of age group on
(95\% CI 1.23 to 2.75 ), before and after adjusting for smoking.

There was also a significant increasing effect of total cumulative dust exposure on breathlessness $(\mathrm{p}=0.008)$, OR $2.15(95 \% \mathrm{CI} 1.22$ to 3.79$)$ and $(\mathrm{p}=0.038)$, OR 1.90 (95\% CI 1.04 to 3.47$)$ before and after adjustment for age and smoking (Table $3)$. There was a very significant increasing effect of duration of underground service up to the end of the second decade on breathlessness grade

Table 3 Prevalence of breathlessness $\geq 2$ in relation to total cumulative exposure to dust

\begin{tabular}{|c|c|c|c|c|c|c|}
\hline Variables & \multicolumn{2}{|c|}{ Breathlessness } & \multicolumn{2}{|c|}{$\begin{array}{c}\text { Odds ratio }(95 \% \mathrm{CI}) \text { (sepa- } \\
\text { rate analysis) }\end{array}$} & \multicolumn{2}{|c|}{$\begin{array}{c}\text { Odds ratio }(95 \%)(\text { simul- } \\
\text { taneous analysis) }\end{array}$} \\
\hline \multicolumn{7}{|l|}{ Age groups (y) } \\
\hline $25-34$ & 183 & 52 & 1.00 & & 1.00 & \\
\hline $35-44$ & 488 & 237 & $1.71 * *$ & (1.21 to 2.41$)$ & 1.31 & $(0.90$ to 1.91$)$ \\
\hline $45-54$ & 173 & 96 & $1.95 * * *$ & (1.31 to 2.90$)$ & 1.33 & (0.85 to 2.09$)$ \\
\hline \multicolumn{7}{|c|}{$\begin{array}{l}\text { Total cumulative exposure } \\
\left(\mathrm{mg} \cdot \mathrm{m}^{-3} \cdot \mathrm{y}\right)\end{array}$} \\
\hline$<10$ & 443 & 148 & 1.00 & & 1.00 & \\
\hline $10-19.99$ & 368 & 214 & $1.74 * * *$ & (1.35 to 2.24$)$ & $1.56^{* *}$ & (1.18 to 2.06$)$ \\
\hline 20-39.99 & 32 & 23 & $2.15^{* *}$ & (1.22 to 3.79$)$ & $1.90^{*}$ & (1.04 to 3.47$)$ \\
\hline \multicolumn{7}{|l|}{ Smoking status } \\
\hline Never smoked & 663 & 281 & 1.00 & & 1.00 & \\
\hline Ever smoked & 180 & 104 & $1.37^{*}$ & (1.03 to 1.80$)$ & 1.24 & $(0.93$ to 1.65$)$ \\
\hline Total $^{\dagger}$ & 843 & 385 & & & & \\
\hline
\end{tabular}

Table 4 Mean lung function indices (\% predicted) in relation to quartile cumulative dust exposure and smoking

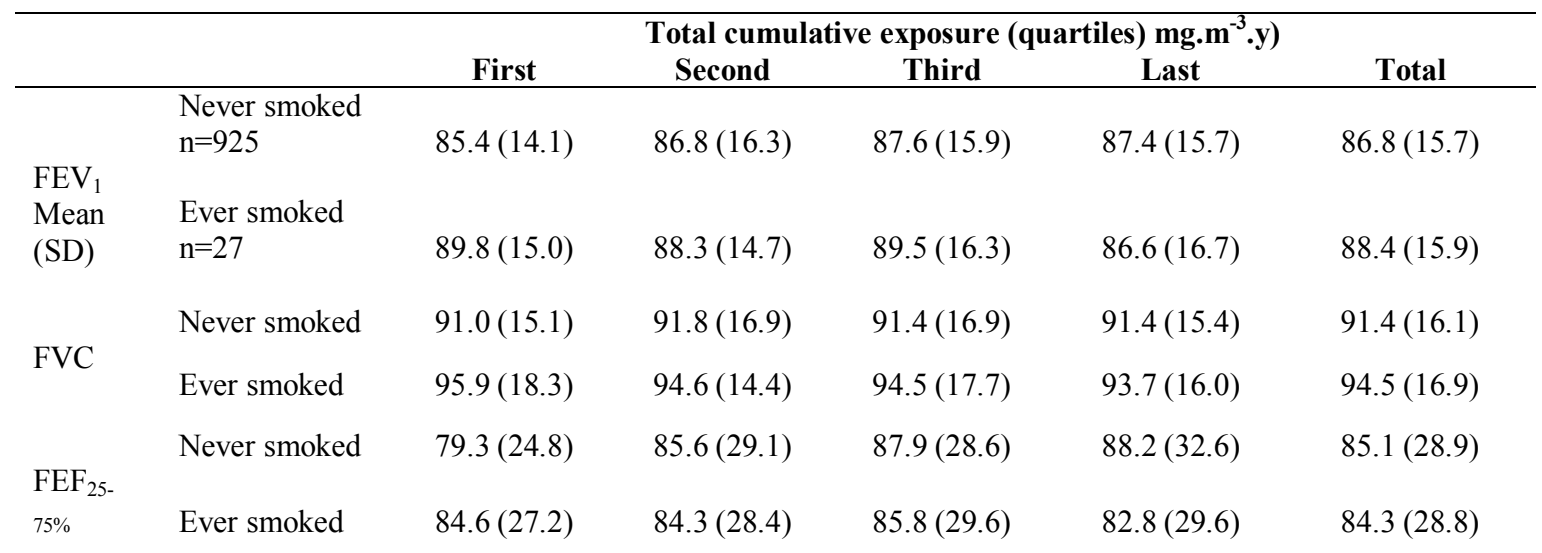

breathlessness was very significant $(\mathrm{p}=0.001)$ OR $1.95(95 \%$ CI 1.31 to 2.90$)$ and $(\mathrm{p}=0.003)$ OR 1.84 $(\mathrm{p}=0.001)$, OR $1.86(95 \%$ CI 1.30 to 2.68$)$ and $(\mathrm{p}=0.017)$, OR $1.63(95 \%$ CI 1.09 to 2.43$)$ both 
before and adjustment for smoking. The declining effect of duration of underground service beyond the second decade on breathlessness was however not significant after adjusting for age and smoking.

\section{Lung Functions}

A total of 1210 of the 1236 subjects were able to achieve acceptable blows. The rest, 26 (2.1\%) could not produce any acceptable blows after eight (8) consecutive manoeuvres. As expected there was a decline in all lung function indices; FVC $(\mathrm{r}=0.239 ; \mathrm{p}=0.000), \mathrm{FEV}_{1} \quad(\mathrm{r}=0.276 ; \mathrm{p}=0.000)$, $\mathrm{FEV}_{1} \% \quad(\mathrm{r}=0.069 ; \mathrm{p}=0.016)$ and $\mathrm{FEF}_{25-75 \%}$ $(r=0.098 ; p=0.001)$ with age.

\section{Determinants of lung functions}

The study population was grouped into four by quartiles of the total cumulative respirable dust exposure (First: 0-5.26, Second: 5.27-10.46, Third: 10.47-14.46, Last: 14.47-33.02 mg.m ${ }^{-3}$.years. Age and smoking increased with increasing quartiles of exposure, so did height and weight. There was no relationship between either $\mathrm{FEV}_{1}$ per cent predicted or FVC per cent predicted and increasing cumulative respirable dust exposure.

Figures 1, 2 and 3 show the profile plots of the spirometric indices across the levels of quartiles of the total cumulative dust exposure.

There was a decline of $3.2 \%$ (89.8 to $86.6 \%)$ in the mean $\mathrm{FEV}_{1}$ (\% predicted), less than $1 \%$ in mean FVC (\% predicted), and $2.0 \%$ (84.8 to $82.8 \%$ ) in the mean $\mathrm{FEF}_{25-75}$ (\% predicted) of the ever smoked with increasing quartiles of total cumulative dust exposure. However, among the never smoked, there was virtually no effect on FVC $(\%$ predicted), while an improvement of $2.2 \%$ (85.4 to $87.6 \%$ ) in $\mathrm{FEV}_{1}$ and $9.0 \%$ (79.3 to $88.3 \%$ ) in $\mathrm{FEF}_{25-75 \%}$ were observed

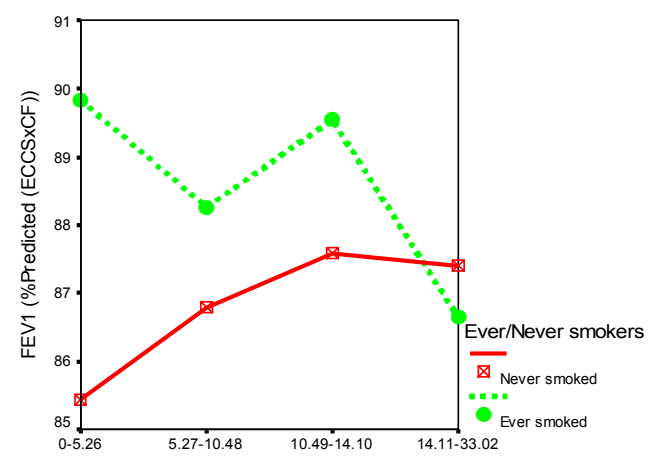

Total Cumulative Exposure (quartile) (mg.m-3.y)

Figure 1 Effects of increasing total cumulative dust exposure on forced expiratory volume in one second $\left(\mathrm{FEV}_{1}\right)$

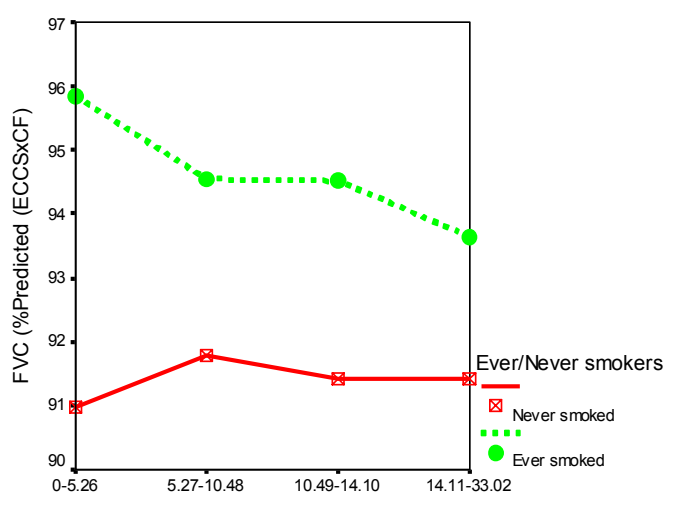

Total Cumulative Exposure (quartile)(mg.m-3.y)

Figure 2 Effects of increasing total cumulative dust exposure on forced ventilatory capacity (FVC)

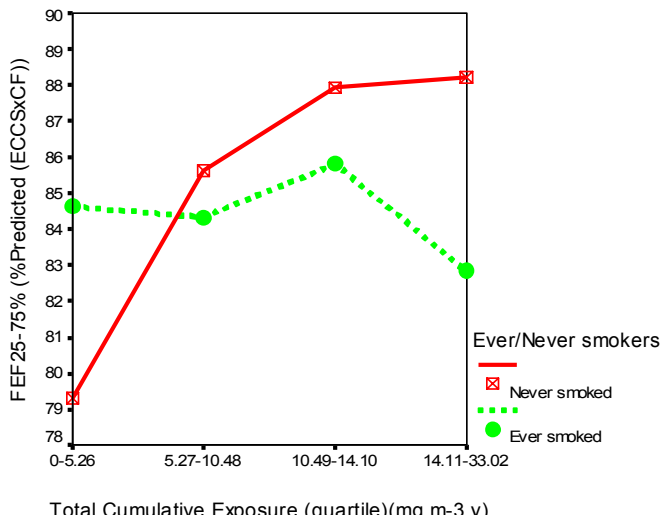

Figure 3 Effects of increasing total cumulative dust exposure on mid-forced expiratory flow $\left(\mathrm{FEF}_{25-75}\right)$.

One distinguishing feature of the percent predicted lung function indices was that the ever smoked started off with larger mean values at lower cumulative dust exposures quartiles than the never smoked. The distribution of the mean and standard deviations of the percent predicted lung function indices in relation to total cumulative dust exposure quartiles and never and ever smokers is shown in Table 4.

Multiple regression analysis showed a significant increasing effect of total cumulative dust exposure on $\mathrm{FEF}_{25-75 \%}(\mathrm{p}=0.011)$, and a significant effect of smoking on FVC ( $\mathrm{p}=0.020)$ (Table 5). There was a significant interaction between smoking and cumulative respirable dust exposure on $\mathrm{FEF}_{25-75 \%}$ $(p=0.009)$, but not on FEV1 or FVC. One standard deviation change in total cumulative exposure $( \pm 5.61 \mathrm{mg} / \mathrm{m} 3$.yrs $)$ resulted in 0.074 standard deviation change in $\mathrm{FEF}_{25-75 \%}$. 
Table 5 Percent predicted lung function values in relation to total cumulative exposure to dust and cigarette smoking

\begin{tabular}{|c|c|c|c|}
\hline & $\begin{array}{c}\text { Total cumula- } \\
\text { tive exposure } \\
\left(\mathrm{mg}^{-3} \cdot \mathbf{m}^{-3} \cdot \mathrm{y}\right) \\
\beta \text { coefficient } \\
\text { (p) }\end{array}$ & $\begin{array}{c}\text { Smoking } \\
\beta \text { coefficient } \\
\text { (p) }\end{array}$ & $\begin{array}{c}\text { Cumulative } \\
\text { exposure } \\
* \text { smoking } \\
\beta \text { coefficient } \\
\text { (p) } \\
\end{array}$ \\
\hline $\begin{array}{l}\mathrm{FEVC}_{1} / \mathrm{F} \\
\mathrm{VC}(\%)\end{array}$ & $-0.039(0.174)$ & $-0.054(0.061)$ & $-0.034(0.247)$ \\
\hline $\mathrm{FEV}_{1}$ & $0.023(0.425)$ & $0.046(0.110)$ & $0.018(0.533)$ \\
\hline FVC & $0.008(0.773)$ & $0.067(0.020)$ & $0.001(0.976)$ \\
\hline $\mathrm{FEF}_{25-75 \%}$ & $0.074(0.011)$ & $-0.010(0.734)$ & $0.076(0.009)$ \\
\hline
\end{tabular}

\section{DISCUSSION}

This is a study of the respiratory health of the 1236 available underground gold miners of the largest and oldest mine in Ghana with a response rate of $84.4 \%$. The prevalence of chronic bronchitis was $21.2 \%$ and breathlessness MRC grade $\geq 231.3 \%$. This study did not include any surface workers, which may have served as a useful control/nonexposed occupational group. However, the main aim of this study was to assess the respiratory morbidity of underground miners as an identifiable group and to compare findings with other international epidemiological underground gold mining studies.

Although the method of administration of the questionnaire in the present study was not the standard one, (interviewer translated freely into the Twi language from the written English version), the level of reproducibility in such an administration has been tested in two studies in Johannesburg workforce and found to be comparable to the standard methods obtained in homogeneous populations in the UK and $\mathrm{USA}^{9,10}$. In the above studies, multiple interviewers translated into various languages of choice of the interviewees.

The limitation encountered was that of information bias. Miners are known to be predisposed towards the underreporting of respiratory symptoms especially chronic bronchitis, as poor performance could result in the failure of renewal of their mining certificates ${ }^{11}$. "Coughing" in Ghana is almost always associated with Pulmonary Tuberculosis, which is a social stigma. Subjects might have refused to answer in the affirmative to the symptom of chronic bronchitis for fear of being considered to have PTB.
On the contrary Sluis-Cremer et al. ${ }^{11}$ have observed the existence of bias in South African gold miners towards over-reporting to questions on breathlessness, which is a personal subjective assessment. They are aware of the potential harmful effects of silica dust in the air they breath, hence their desire for compensation. Despite the high response rate, some of the miners felt that the study was being used as a "witch-hunt" by the management to get rid of the weak and/or sick ones amongst them, and so if they performed poorly in the survey they might be made redundant, though it was clearly impressed upon the miners of the absolute independence and non-interference of the study. To avoid a social stigma, their responses might have been low to cough and sputum, but not to breathlessness.

\section{Respiratory Symptoms}

The prevalence of chronic bronchitis in the general population in most developed countries is between $3 \%$ and $17 \%$, while higher rates of between $13 \%$ and $27 \%$ exist in the developing countries ${ }^{12}$. However, at present there is no reliable data on the prevalence of chronic bronchitis in the general Ghanaian population. The overall prevalence of chronic bronchitis found in the present study was $21.2 \%$, while that of breathlessness $\geq 2$ was $31.3 \%$. Though this level of chronic bronchitis is comparable to those observed in the general population in the developing world, and $14 \%^{11}$ and $27 \%^{13}$ in Australian gold miners, it was lower than $39.3 \%{ }^{12}$ and $62 \%{ }^{14}$ reported among South African gold miners. Far lower prevalence levels of respiratory symptoms of $0.1 \%$ have been found in copper miners of Zimbabwe ${ }^{15}$. Lower prevalence levels of $2.3 \%$ of chronic bronchitis in 852 South African gold miners were reported to be associated with low cigarette smoking rates and/or the smoking of pipe with very little or no inhalation of smoke ${ }^{16}$.

Despite the low prevalence $(23 \%)$ of the ever smoked, and with a mean daily consumption of 4 cigarettes in the present study, the prevalence of chronic bronchitis in smokers was significantly higher than in the never smoked. Mokotetle et al. ${ }^{10}$, Sluis-Cremer et al. ${ }^{11}$ and Hnizdo et al. ${ }^{17}$ have found that chronic bronchitis tends to increase sharply with smoking in gold miners. According to Sluis-Cremer et al. what is important in the causation of chronic bronchitis is the fact that one smokes, but not the daily tobacco consumption. They observed a major increase in the incidence of chronic bronchitis between the 'no smoking' and 'light smoking.' The present study has also ob- 
served a statistically significant effect of smoking on chronic bronchitis. For miners who had never smoked, no significant relationship was found between chronic bronchitis and age, mining experience (total duration of underground service) or the personal respirable dust exposure levels (both current and cumulative).

In the present study the prevalence of chronic bronchitis was found to be related to a current underground occupation. The effect of tipping/rockbreaking on chronic bronchitis was significant $(\mathrm{p}=0.045)$, OR 1.93 (95\% CI 1.02 to 3.67$)$, before adjustment for age and smoking. Tipping/rockbreaking as well as drilling are the occupational groups with current exposure to dust more than 1.0 $\mathrm{mg} \cdot \mathrm{m}^{-3}$ and silica concentrations of 0.06 and 0.07 $\mathrm{mg} \cdot \mathrm{m}^{-3}$ respectively.

There was a statistically significant effect of increasing age, mining experience and total cumulative respirable dust exposure on the prevalence of breathlessness. The effect of the total duration of underground service (mining experience) on breathlessness increased to a peak at about 20 years and then declined. The decline was however not significant after the adjustment for smoking. This could be attributed to the 'survivor population' with the long service. There was a significant effect of blasting and tipping/rock-breaking on the prevalence of breathlessness. There was a steep rise in the prevalence of mean breathless grade in the ever smoked with increasing quartiles of total cumulative exposure, but less so in the never smoked. The occupational effect on breathlessness in the miners was therefore much more pronounced in smokers than non-smokers.

\section{Lung function tests}

All the measured lung function indices declined with age, as expected, as the functional efficiency of the lung deteriorates with age ${ }^{18}$. The present study with relatively low cumulative silica exposure has shown no significant effect, as obtained in multiple regression analysis, of increasing total cumulative exposure to respirable dust in the mine on the mean $\mathrm{FEV}_{1}$ (\% predicted), mean $\mathrm{FEV}_{1} / \mathrm{FVC}$ ratio and mean FVC (\%predicted), but there is a significant increasing effect of total cumulative respirable dust exposure and the combined effect of smoking and total cumulative respirable dust exposure on mean $\mathrm{FEF}_{25-75 \%}$ (\% predicted) $(\mathrm{p}=0.011$ and $\mathrm{p}=0.009$ respectively), while a significant increase in mean FVC was observed with smoking $(\mathrm{p}=0.020)$.
Becklake et al. ${ }^{19}$ observed an increasing $\mathrm{FEV}_{1}$ decline with increasing dust exposure in both smokers and non-smokers. Sluis-Cremer et $a l^{20}$, and Søyseth et $a l^{21}$ have reported that any disabling ventilatory function loss is more likely to be due to cigarette smoking (active or passive), and that the slope was steeper with increasing exposure level to increasing risk $^{22}$. Hnizdo ${ }^{23}$ also found nonsmoking miners in the highest dust category to have better $\mathrm{FEV}_{1}$ than even non-miners smoking one pack a day.

There appears to be a health selection out of the workforce due to respiratory ill health, which may attenuate exposure-response relationships in the miners, resulting in a "survivor population" and a "healthy worker" effect in the present study. Such a bias, according to McDonald, in Ernst et $a l^{24}$ is especially strong in cross sectional studies such as the present one, where the workforce studied represents a survivor population. Hnizdo et al. ${ }^{17}$ also observed that the consistent increase in the lung function measurement in the highest dust exposure category might be due to systematic effect, possibly a healthy worker effect.

The best explanation for low or lack of respiratory impairment in the Ghanaian gold miners is low level of silica content of the respirable dust in the mine. The prevalence of respiratory impairment is known to be lower in coalmine dust than gold mine dust due to the higher fractional content of silica in the gold mine dust ${ }^{1,25}$.

Ever smokers were found to have larger values than the never smoked at lower exposure levels which decline faster with never smokers attaining larger values at the higher exposure levels in $\mathrm{FEV}_{1}$ (\% predicted) and $\mathrm{FEF}_{25-75 \%}(\%$ predicted). In the present study, total cumulative exposure to dust is directly related to age of the miners (as the difference between higher and lower exposed jobs was small), and as has been observed by Ferris et al. ${ }^{31}$ in Germany and Mokoetle et al. ${ }^{10}$, Oleru ${ }^{26}$, and Becklake et $a .^{27}$ in various parts of Africa, smokers have larger mean vital $\mathrm{FVC}$ and $\mathrm{FEV}_{1}$ at earlier ages than non-smokers do. This they said was due to the "healthy smoker" effect, because the individual who takes up smoking has lungs, which are relatively resistant to the effects of smoking, as they have lower levels of airway responsiveness to inhaled materials. This phenomenon, according to Becklake et al. is not limited to person, place or time, and that it is most frequent in the ever smoked (current and ex-) before the age of 40 . 
Due to reasons which are not biologically clear, persons who establish smoking at an earlier age may have certain morphological differences from non-smokers. Seltzer ${ }^{28}$ found the chest circumference relative to height of smokers in the 1942 Harvard University entrants to be greater than the non-smokers. The present study found the mean height of the ever smoked $(170.2 \mathrm{~cm})$ to be $1 \mathrm{~cm}$ taller than the never smoked $(169.1 \mathrm{~cm})$.

Such preferential susceptibility of smokers to dust exposure as illustrated in Figure 1 in the present study has also been documented by the above authors, while an $\mathrm{FEV}_{1}$ decline in ever smokers has been reported by Trethowan et al. $^{29}$ among ceramic fibre workers. There was a dose-related effect with increasing exposure in the ever smoked (current and ex-smokers), but none in the never smoked. The potentiating effect of cigarette smoking and cumulative dust exposure on ventilatory function loss in the ever but not the never smoked demonstrates both "healthy smoker", as well as "healthy worker" effects in the Ghanaian miners as they tend to survive with increasing exposure.

\section{CONCLUSION AND RECOMMEN- DATIONS}

The marginal effects of occupational factors on the respiratory health (breathlessness and $\mathrm{FEF}_{25-75 \%}$ ) of the Ghanaian underground gold miner in such a cross-sectional survey should be treated with caution. Before an evidence of lack of risk in the mine could be ascertained, a longitudinal survey would need to be carried out. There is the need for such a prospective study to directly relate the respiratory impairment to measured personal total inhalable and respirable dust exposures.

\section{ACKNOWLEDGEMENT}

This paper is part of the study submitted to the University of Birmingham, UK, for the award of a $\mathrm{PhD}$ by FY Bio in 2003. The authors wish to acknowledge the immense support of the study subjects (the miners) as well as the management of the Obuasi mine. We are also grateful to the staff of the Institute of Occupational and Environmental Medicine, The University of Birmingham, UK. The $\mathrm{PhD}$ was fully sponsored by the Government of Ghana.

\section{REFERENCES}

1. Oxman AD, Muir DCF, Shannon HS, Stock SR, Hnizdo E, Lange HJ. Occupational dust exposure and chronic obstructive pulmonary disease. A systematic review. Am Rev Respir Dis 1993; 148: 38-48.

2. Hnizdo E, Sluis-Cremer GK. Silica exposure, silicosis and lung cancer: a mortality study of South African gold miners. $\mathrm{Br} J$ Ind Med 1991; 48(1): 53-60.

3. Bio FY, Sadhra S, Jackson C and Burge PS. Respirable dust exposure in underground gold miners at Obuasi in Ghana. Journal of University of Science \& Technology 2006; 26(1): 14 -21 .

4. Medical Research Council. Respiratory Symptoms questionnaire (1986). British Medical Research Council. London, England.

5. International Union Against Tuberculosis and Lung Disease. Bronchial Symptoms Questionnaire-1986. London, England.

6. American Thoracic Society. Standardisation of spirometry: 1994 Update. Am J Respir Crit Care Med 1995; 152: 1107-1136.

7. Quanjer PhH, Tammeling GJ, Cotes JE et al. Standardised Lung function testing: Lung volumes and forced ventilatory flows - 1993 update. Eur Respir J 1993; 6(Suppl 16): 5-40.

8. SPIDA spirometry software; 2001: Version 1.0.1.

9. Becklake MR. Freeman S. Goldsmith C. Hessel PA. Mkhwelo R. Mokoetle K. Reid G. Sitas F. Respiratory questionnaires in occupational studies: their use in multilingual workforces on the Witwatersrand. Int J Epidemiol 1987; 16: 606-611.

10. Mokoetle KE, de Beer M, Becklake MR. A respiratory survey in a black Johannesburg workforce. Thorax 1994; 49: 340-346.

11. Sluis-Cremer GK, Walters LG, Sichel HS. Chronic bronchitis in miners and non-miners: an epidemiological survey of a community in the gold mining area in the Transvaal. Br J Ind Med 1967a; 24: 1-12.

12. Ball $\mathrm{P}$, Make B. Acute exacerbation of chronic bronchitis. An international comparison. Chest 1998; 113(3 suppl): 199s-204s. 
13. McNulty JC. Malignant pleural mesothelioma in an asbestos worker. In Musk AM, de Klerk NH, Eccles JL, Hobbs MST, Armstrong BK, Layman L, Mcnulty JC. Wittenoom, Western Australia: A Modern Industrial Disaster. Am J Ind Med 1992; 21: 735-747.

14. Cowie RL, Mabena SK. Silicosis, chronic airflow limitation and chronic bronchitis in South African gold miners. Am Rev Respir Dis 1991; 143(1): 80-84.

15. Paul R. Silicosis in Northern Rhodesia copper mines. Arch Envtal Hlth 1961; 2: 96-109.

16. Sluis-Cremer GK. Harrison WO. Pearson RC. Respiratory symptoms and lung function in black and white mining and non-mining industrial workers in South Africa. S Afr Med J 1981; 59(19): 672-675.

17. Hnizdo E, Baskind E, Sluis-Cremer GK. Combined effect of silica dust exposure and tobacco smoking on the prevalence of respiratory impairment among gold miners. Scand J Work Environ Hlth 1990; 16: 411-422.

18. Cotes JE, Russiter CE, Higgins ITT, Gilson JC. Average normal values for the forced expiratory volume in white Caucasian males. $\mathrm{Br}$ Med $J$ 1966; 18(88 suppl.): 128-136.

19. Becklake MR. Fournier-Massey G. Rossiter CE. McDonald JC. Lung function in chrysotile asbestos mine and mill workers of Quebec. Archives of Environmental Health 1972; 24(6): 401-409.

20. Sluis-Cremer GK, Sichel HS. Ventilatory function in males in a Witwatersrand town. Am Rev Respir Dis 1968; 98: 229-239.

21. Søyseth V, Boe J, Kongerud J. Relation between decline in FEV1 and exposure to dust and tobacco smoke in aluminium pot room workers. Occup Environ Med 1997; 54: 27-31.
22. Parkes WR. Pneumoconiosis associated with coal and other carbonaceous materials. In Brichet A, Salez F, Lamblin C and Wallaert B, eds. Coal workers' pneumoconiosis and silicosis. European Respiratory Monograph 1999; 4(11): 136-157.

23. Hnizdo E. Loss of lung function associated with exposure to silica dust and with smoking and its relation to disability and mortality in South African gold miners. $\mathrm{Br} J$ Ind Med 1992; 49(7): 472-479.

24. McDonald JC. Epidemiology. In: Ernst P, Dales RE, Nunes F, Becklake MR. Relation of airway responsiveness to duration of work in a dusty environment. Thorax 1989; 44: 116120.

25. Sluis-Cremer GK, Walters LG, Sichel HS. Ventilatory function in relation to mining experience and smoking in a random sample of miners and non-miners in a Witwatersrand town. Br J Ind Med 1967b; 24: 13-25.

26. Oleru UG. Pulmonary function of control and industrially exposed Nigerians in asbestos, textile and toluene diisocyanate foam factories. Environ Res 1980; 23: 137-148.

27. Becklake MR, Lalloo U. The 'healthy smoker': A phenomenon of health selection? Respiration 1990; 57: 137-144.

28. Seltzer CC. Morphologic constitution and smoking. JAMA 1963; 183: 639.

29. Trethowan WN, Burge PS, Rossiter CE, Harrington JM, Calvert IA. Study of the respiratory health of employees in seven European plants that manufacture ceramic fibres. Occup Environ Med 1995; 52: 97-104. 